Balos, M.M., et al., Araceae Familyasına Ait Bazı Taksonların Süt Pıhtılaştırma Özelliklerinin Araştırılması. International Journal of Life Sciences and Biotechnology, 2021. 4(3): p. 412-419.

DOI: $10.38001 /$ ijlsb.889548

\title{
Araceae Familyasına Ait Bazı Taksonların Süt Pıhtılaştırma Özelliklerinin Araştırılması
}

\author{
Mehmet Maruf Balos ${ }^{1(i)}$, Hasan Akan ${ }^{*}{ }^{(i)}$, Eda Nur Durmaz ${ }^{3}$, Fatma Zehra \\ $\dot{I}_{\operatorname{lgaz}}{ }^{3}$ iD
}

\section{ÖZET}

Bu çalışmanın amacı Aracea familyasına ait Biarum aleppicum, Biarum bovei, Arum rupicola gibi bazı bitkilerin yumru ve yapraklarından süt pıhtılaştırma özelliklerinin araştırılarak doğal bir yöntemle yoğurt üretmektir. Yaptığımız çalışmada sütün pıhtılaştırılmasında kullanılan bitkilerin kök yumruları dilimlenerek, yaprakları ise doğranarak doğrudan kullanılmıştır. Mayalama işleminin ikinci kez tekrarlanması ve ikinci işlemden sonra elde edilen yoğurt renginin daha beyaz, akışkanlığının daha katı olduğu, tadının daha tatlı olduğu görülmüştür. Yaptığımız bu çalışma ile daha önce kullanımına rastlanmamış olan Biarum aleppicum, Biarum bovei, Arum rupicola bitkilerinin yumru kök ve yaprakları kullanılarak yoğurt benzeri tatlı süt pıhtısı elde edilmiştir.

\author{
MAKALE GEÇMİŞi \\ Geliş \\ 02 Mart 2021 \\ Kabul \\ 14 Nisan 2021 \\ ANAHTAR KELIMELER \\ Biarum aleppicum, \\ Biarum bovei, \\ Arum rupicola, \\ Süt pıhtılaştırma
}

\section{Investigation of milk coagulation properties of some taxa belonging to the Araceae family}

\begin{abstract}
The aim of this study is to investigate the milk coagulation properties of some plants such as Biarum aleppicum, Biarum bovei and Arum rupicola belonging to the Aracea family, and to produce yoghurt with a natural method. In our study, the root tubers of the plants used in the coagulation of milk were sliced and the leaves were chopped directly. After the second repetition of the fermentation process and the second process, it was observed that the color of the yoghurt obtained was whiter, its fluidity was stronger, and its taste was sweeter. With this study, yoghurt-like sweet milk clot was obtained by using tubers and leaves of Biarum aleppicum, Biarum bovei, Arum rupicola plants, which were not used before.
\end{abstract}

\author{
ARTICLE HISTORY \\ Received \\ 02 March 2021 \\ Accepted \\ 14 April 2021 \\ KEY WORDS \\ Biarum aleppicum, \\ Biarum bovei, \\ Arum rupicola, \\ milk coagulation
}

\section{Giriş}

Yoğurt, eski çağlardan beri kullanılmaktadır. Mayalandırılmış süt mamulleri daha çok göçebe topluluklar tarafından geliştirildiği belirtilmektedir. İlk zamanlardaki insanların

\footnotetext{
${ }^{1}$ Fatma Zehra Kız Anadolu İmam Hatip Lisesi, Akbayır, 1063. Sk. No:2, 63320 Karaköprü/Şanlıurfa ${ }^{2}$ Harran Üniversitesi, Fen edebiyat Fakültesi, Biyoloji Bölümü, Osmanbey kampüsü, 63300. Şanlıurfa ${ }^{3}$ Milli İrade K1z Anadolu İmam Hatip Lisesi, Akpıyar Mahallesi, Gap Blv. 129/A, 63320 Karaköprü/Şanlıurfa

* Sorumlu Yazar: Hasan Akan, e-mail: hakan@harran.edu.tr
} 
sütü hayvan derilerinde muhafaza edip, daha sonra ekşime ve pıhtılaşmaya bıraktıkları tahmin edilmektedir. Yoğurt ilk kez Türkler tarafından Anadolu'ya getirilmiş olup, Avrupa'ya da zamanla tanıtmışlardır [1,2].

Bitkilerin alışılagelmiş kullanımlarından biri süt pıhtılaşmasıdır. Asidik bileşiklerin 1sıtılması ve eklenmesi, iyi kültürlenmiş mikrobiyal maddeler, sütü yoğurt ve peynir gibi pıhtılaştırıcı ürünlere dönüştüren enzimler gibi birçok alternatif vardır. Sütün enzimatik yöntemlerle pıhtılaştırılması, çoğu peynirin üretiminde temel bir adımdır. Öte yandan, süt hayvancılığı çiftliklerinde, iyi kültürlenmiş bakteriler yoğurt yapmak için kullanılır ve süte en s1k eklenen iki bakteri Lactobacillus bulgaricus ve Streptococcus thermophiles'dir. Ev düzeyinde enzimler ve bakteriler gibi pıhtılaştırıcı ajanlar elde etmek zor olduğundan, bazı bölgelerde yöre halkı bunun yerine doğal ortamlarında bulunan bitki özlerini kullanma geleneği geliştirmişlerdir. Belirtilen alanda bu bitkilerin kullanımı çoğunlukla yoğurt oluşumunu kolaylaştıracağı varsayımıyla yapılsa da bitkilerin kimozin gibi davranan enzimleri serbest bırakabildikleri için peynir oluşturma olasılığını da güçlendirmektedir. Öte yandan, bitki özlerinin sentetik ilaçlara ve gıda katkı maddelerine göre daha az risk oluşturduğu düşünülmektedir [3].

Bitkisel pıhtılaştırıcıların kullanılması çok eskiye dayanmaktadır. Son yıllarda ise bitkisel pıhtılaştırıcıların süt teknolojisinde kullanımı dikkat çekici oranda artış göstermiştir. Bazı bitkilerde doğal olarak bulunan, sütü pıhtılaştırma yeteneğine sahip pıhtılaştırıcı enzimlerden yararlanılarak süt pıhtılaştırılabilmektedir. Bu bitkisel kökenli enzimler, bitkilerin kök, gövde, tohum, çiçek ve yaprak gibi kısımlarının kullanılmasıyla veya belirli bölgelerinden elde edilmektedirler [3].

Türkiye zengin bir floraya sahiptir. Türkiye'de 167 familya, 1320 cins ve bu cinslere ait toplam 11707 takson bulunmaktadır. Taksonlardan 3649ü Türkiye için endemiktir [4]. Anadolu bitki bilgeliğinde bazı bitkilerin pıhtılaştırıcı olarak kullanılmaktadır. Süt pıhtılaştırma özelliğiyle bilinen önemli bitkiler arasında incir (Ficus carica L.), altın çilek (Physalis peruviana L.), teleme otu (Euphorbia maculata L.), kenger otu (Gundelia tournefortii L.), nohut (Cicer arietinum L.) gelmektedir [3]. Bu çalışmada ise Araceae familyasına ait bazı taksonların sütü pıhtılaştırma özellikleri araştırılmıştır.

Araceae (Yılanyastı̆ğgiller) familyası 105 cins ve 3300 tür içerir [5]. Araceae Juss. (Yılanyastığıgiller) familyasında yer alan Biarum Schott (Yılanpancarı) cinsi dünyada 21, ülkemizde 11 tür ve 6 alt türle temsil edilmekte olup, endemik takson sayısı 2'dir. 
Arum L. dünya genelinde 32, ülkemizde 17 tür ve tür altı taksonla temsil edilmekte olup, 3 taksonu endemiktir $[6,7,8,9,10,11]$.

Yapılan literatür araştırmasında, ülkemizdeki bazı bitkilerin geleneksel olarak süt pıhtılaştırılmasında kullanıldığı görülmüş̧ür [3, 12, 13, 14, 15].

Bu çalışmada süt pıhtılaştırma özelliğinin olup olmadığı bugüne kadar araştırılmayan Arum rupicola Boiss., Biarum aleppicum J.Thiébaut ve Biarum bovei Blume gibi baz1 bitkilerin sütü pıhtılaştırma özelliklerinin araştırılması amaçlanmıştır.

\section{Materyal ve Metot}

\section{Numunelerin toplanması ve hazırlanması}

Çalışmada kullanılan bitkiler, Güneydoğu Anadolu Bölgesinde tarafımızca toplanmış ve Harran üniversitesi herbaryumunda saklanmıştır (Şekil 1). Bitki örnekleri Türkiye Florası [16] isimli eserden yararlanılarak teşhis edilmiştir. Araştırmada kullanılan bitkilerin bilimsel isimleri, yerel ve Türkçe isimleri [4] Tablo 1'de verilmiştir.

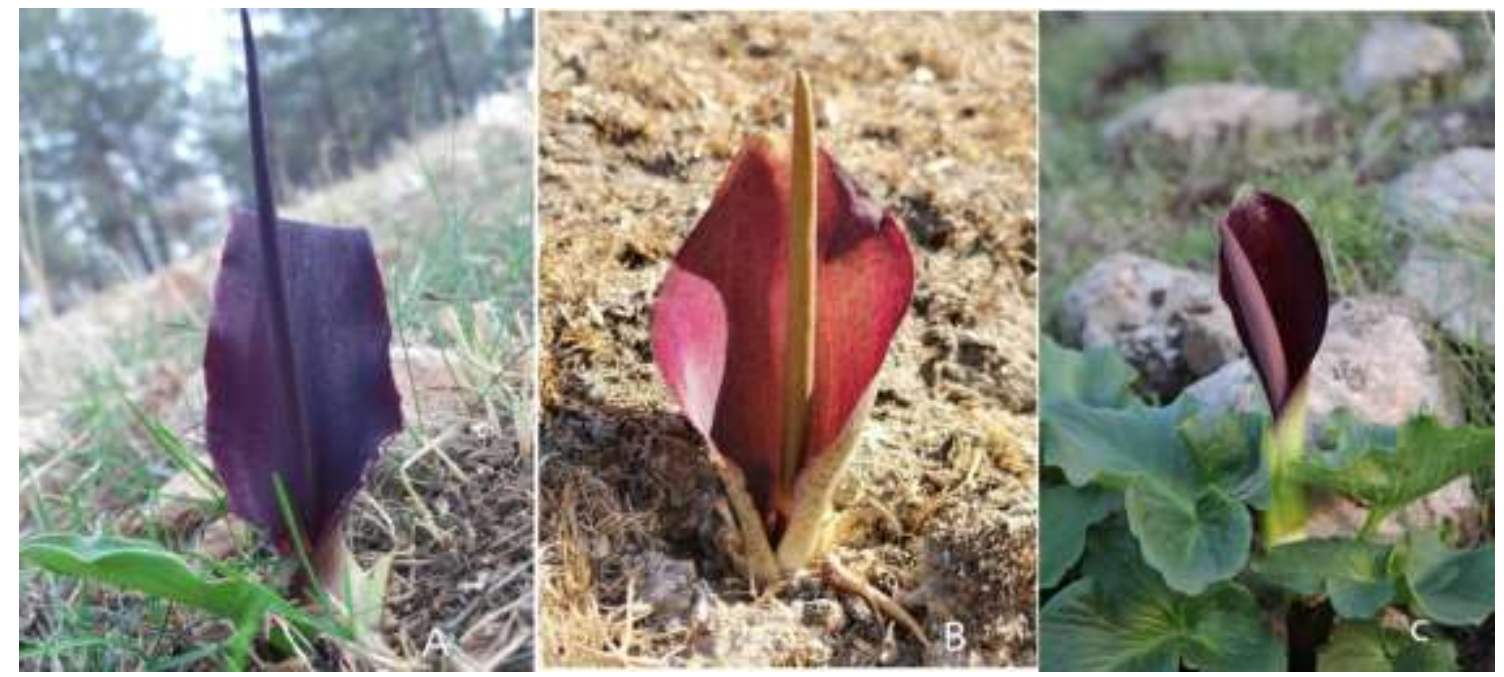

Şekil 1 Araştırmada kullanılan bitkilerin genel görüntüsü; A-B. aleppicum, B-B. bovei, C-A. rupicola 
Tablo 1 Süt pıhtılaştırma yapımında kullanılan bitkilerin bilimsel ve yöresel isimleri ile yayılış durumlar1

\begin{tabular}{|l|l|l|}
\hline Bitkinin Bilimsel Adı & Bitkinin yöresel isimleri & Ülkemizdeki yayılışı \\
\hline Arum rupicola & Yılanyastı̆̆ı, gavurpancarı, kardi & $\begin{array}{l}\text { Akdeniz ve Güneydoğu Anadolu } \\
\text { Bölgeleri }\end{array}$ \\
\hline Biarum aleppicum & Urfa yılanpancarı, kardi & Güneydoğu Anadolu Bölgesi \\
\hline Biarum bovei & Özge sucukotu, kardi & $\begin{array}{l}\text { Akdeniz, Doğu Anadolu ve } \\
\text { Güneydoğu Anadolu Bölgeleri }\end{array}$ \\
\hline
\end{tabular}

\section{Sütün pıhtılaştırma aşamaları}

Sütün pıhtılaştırılmasında kullanılan bitkilerin yumruları dilimlenerek doğrudan kullanılmıştır. Kaynatma işlemi uygulanmış taze süt, $38-40^{\circ} \mathrm{C}^{\prime}$ ye kadar soğutularak üzerine dilimlenmiş yumrular eklenmiştir. Bir tatlı kaşığı şeker ve tuz eklenerek karıştırıldı. Kavanozların üzeri hava ve ışık almayacak şekilde örtüldü. 8 saat sürenin sonunda kavanozlar buzdolabına alınarak 1 gün bekletildi. Mayalanmaya bırakılan süt buzdolabından alınarak içinden bitki yumruları çıkarıldı. Elde edilen pıhtı vizkozite açısından akışkan olup bir sonraki işlem için maya olarak kullanıldı. Mayalama işlemi ikinci kez tekrarland. İkinci işlemden sonra elde edilen yoğurt renginin daha beyaz, vizkozitesinin daha katı ve tadının daha tatlı olmasına dikkat edildi. Kullanılan bitki materyalleri şekil 2'de, ilk mayalanma süreci sonundaki görüntüler şekil 3'te, ikinci mayalanma sürecindeki görüntüler şekil 4'de verilmiştir.



Şekil 2 Kullanılan bitki materyalleri, A-B. bovei yaprak, B-B. aleppicum yumru, C- B. bovei yumru, D-A. rupicola yumru 




Şekil 3 İlk mayalanma süreci sonundaki görüntüler, A- B.bovei yumru, B. bovei yaprak, $B$. aleppicum yumru, A. rupicola yumru

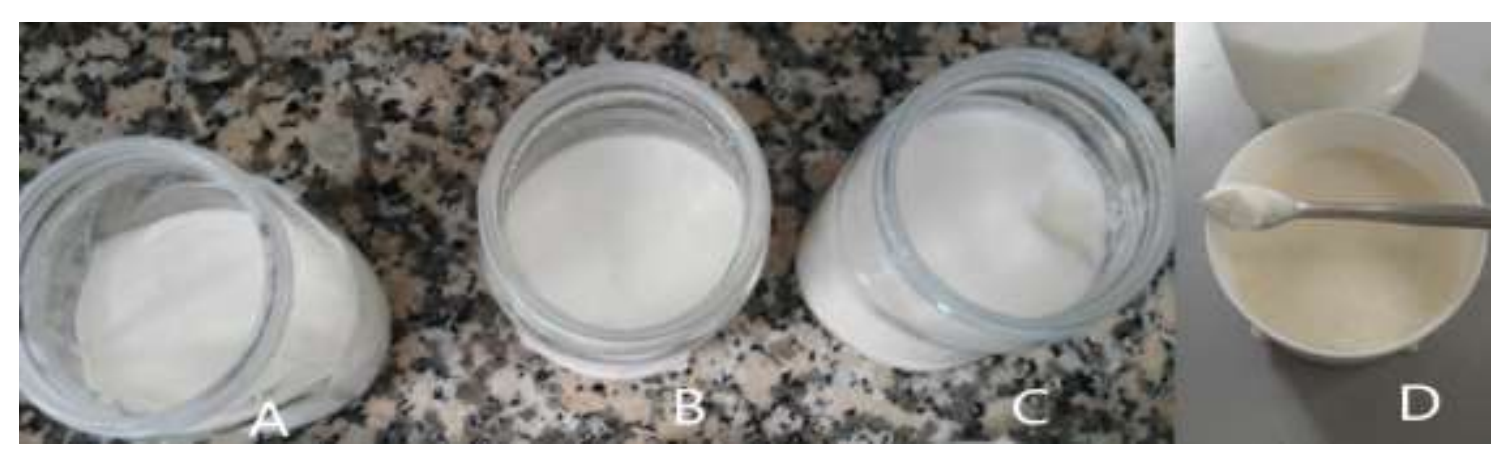

Şekil 4 İkinci mayalanma süreci sonundaki görüntüler A- A. rupicola yumru, B-B. aleppicum yumru, C- B. bovei yumru, D- B. bovei yaprak

\section{Bulgular}

Elde edilen süt pıhtıları için duyusal analiz formu (Ek-1) düzenlenmiş ve sonuçlar Tablo 2'de verilmiştir.

Tablo 2 Duyusal analiz değerlendirmesi sonuçları

\begin{tabular}{|c|c|c|c|c|c|c|c|c|c|c|c|c|}
\hline \multirow{2}{*}{ Numune } & \multicolumn{4}{|c|}{ 1.gün } & \multicolumn{4}{|c|}{ 7.gün } & \multicolumn{4}{|c|}{ 14.gün } \\
\hline & 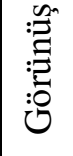 & 傿 & 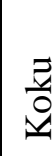 & $\stackrel{\tilde{\pi}}{\pi}$ & 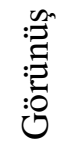 & 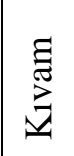 & $\frac{\vec{z}}{Q}$ & $\stackrel{\tilde{\sigma}}{\sigma}$ &  & 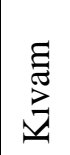 & $\frac{\bar{z}}{a}$ & 胥 \\
\hline $\begin{array}{l}\text { Biarum } \\
\text { aleppicum }\end{array}$ & 10 & 8 & 6 & 6 & 8 & 6 & 6 & 5 & 6 & 6 & 5 & 4 \\
\hline $\begin{array}{l}\text { Biarum } \\
\text { bovei }\end{array}$ & 10 & 10 & 7 & 7 & 8 & 7 & 6 & 5 & 6 & 8 & 5 & 4 \\
\hline $\begin{array}{l}\text { Arum } \\
\text { rupicola }\end{array}$ & 10 & 9 & 6 & 6 & 8 & 6 & 6 & 5 & 6 & 8 & 5 & 4 \\
\hline
\end{tabular}


Elde edilen pıhtıların görünüş, kıvam (vizkozite), koku ve tatları istenilen özellikte çıkmıştır. pH ölçümleri ortalama 5.30-4.80 arasında değerler ile ölçülmüş ve istenilen pH aralığında olduğu görülmüştür. Örnekler içerisinde en çok beğenilen numunenin Biarum bovei'nin olduğu görülmüştür. Değerlendirme sonucunda örneklerin bir haftalık muhafaza süresince görünüş ve diğer özelliklerinde fazla bir değişkenlik olmadığ1 görülmüştür. Muhafaza süresinin sonu olan 14. günde yapılan analizlerde ise görünüş ve diğer özelliklerin bozulduğu gözlenmiştir.

\section{Sonuç ve Tartışma}

Bitkisel pıhtılaştırıcıların kullanılması çok eskiye dayanmaktadır. Dünyada bitkisel pıhtılaştırıcılar İtalya, İspanya, Portekiz, Hindistan, İsrail ve Fas gibi birçok ülkede peynir ve yoğurt yapımında kullanılmaktadır. Düşük maliyete sahip bu bitkisel enzimlerin endüstride kullanımına yönelik araştırmaların arttırılması gerekmektedir [3].

Fermente ürünlerin üretiminde problemlerle karşılaşmamak için ülkemiz süt sanayiinde genetik olarak tanımlanmış ve teknolojik özellikleri belirlenmiş starter kültürler (maya) kullanılmaktadır. Tüm fermente ürünlerde kullanılan starter kültürler yurt dışından alınmaktadır. Bu da ülke ekonomisine yük getirmektedir.

Yapılan deneylerde gerek Arum gerekse Biarum bitkilerinden elde edilen yoğurdun diğer yoğurtlara oranla daha tatlı olduğu görülmüsstür, yoğurdun tadına bakan kişilerde tatlı bir izlenim bırakmıştır. Daha önce denenmemiş bir yöntemle tamamen doğal bir yoğurt yapılmıştır. Ayrıca yoğurdun tatlı oluşunun çocuklar için cezbediciliği bulunmaktadır.

Say ve Güzeler [3] tarafından yapılan diğer bir çalışmada sütü pıhtılaştırma özelliğine sahip önemli bitkiler arasında incir (Ficus carica), altın çilek (Physalis peruviana), teleme otu (Euphorbia maculata), kenger otu (Gundelia tournefortii) ve nohut (Cicer arietinum) gibi bitkilere rastlanmıştır. Yaptığımız bu çalışmada ise Aracea familyasına ait bazı taksonların daha önce kullanımına rastlanmamış olup, bu bitkilerin yumru kök ve yaprakları kullanılarak yoğurt benzeri tatlı süt pıhtısı elde edilmiştir. Düşük maliyete sahip bu bitkisel enzim ve bakterilerin endüstride kullanımına yönelik araştırmaların arttırılması gerekmektedir. Etnobotanik kullanımı olan başka türler üzerinde de araştırmaların yapılması önerilmektedir.Bu çalışma ve bundan sonra yapılacak benzeri çalışmaların ülke ekonomisine katkı sağlayacağını ümit etmekteyiz. 


\section{Kaynaklar}

1. Baysal, A., Yoğurt: Küreselleşen Türk Besini, Türk Mutfak Kültürü Üzerine Araştırmalar, Türk Halk Kültürünü Araştırma ve Tanıtma Vakfı Yayınları, 2002. 30: p.1-8.

2. Şireli, U. ve B. Onaran, Yoğurt ve yoğurdun İnsan sağlı̆̆ı açısından yararları. Ankara Üniversitesi Veteriner Fakültesi Dergisi, 2012: p. 1-4.

3. Say, D., M. Soltani, N. Güzeler, Süt ürünlerinde kullanılan bitkiler. III. Geleneksel Gıdalar Sempozyumu, 10-12 Mayıs, 2012: p. 390-391.

4. Güner, A. ve ark., Türkiye bitkileri listesi (damarlı bitkiler). 2012, İstanbul: Nezahat Gökyiğit Botanik Bahçesi ve Flora Araştırmalar Derneği Yayını.

5. Mayo, S.J., J. Bogner, and P.C. Boyce, The Genera of Araceae. 1997, UK: Kew Royal Botanic Gardens.

6. Akan, H., and M.M. Balos, Check-list of the genus Biarum Schott in the Flora of Turkey, with a new record for Turkey: Biarum syriacum (Spreng.) H. Riedl. Turkish Journal of Botany, 2008. 32(4):305-310.

7. Yıldırım, H., ve ark., Biarum aleppicum J. Thiébaut (Araceae): Türkiye için yeni bir tür kayd1. Bağbahçe Bilim Dergisi, 2016. 3(1): p. 41-46.

8. Yıldırım, H., Arum. Şu eserde: Resimli Türkiye Florası 2: 545-574. Güner, A, Kandemir, A, Menemen, Y, Yıldırım, H, Aslan, S, Ekşi, G, Güner, I. ve Çimen, AÖ (edlr.). 2018, ANG Vakfı Nezahat Gökyiğgit Botanik Bahçesi Yayınları, İstanbul, Türkiye.

9. Güner, A., ve ark., Resimli Türkiye Florası Cilt 2. 2018, ANG vakfı Nezahat Gökyiğit Botanik Bahçesi Yayınları, İstanbul.

10. Çeçen, C., H. Akan, ve M. M. Balos, Şanlıurfa yöresinde doğal yayılış gösteren Biarum Schott (Araceae Juss.) cinsine ait taksonların anatomik ve morfolojik yönden incelenmesi. Kahramanmaraş Sütçü İmam Üniversitesi Tarım ve Doğa Dergisi, 2019. 22: p. 6983.

11. Çeçen, C., H. Akan, ve M. M. Balos, Şanlıurfa yöresinde doğal yayılış gösteren Arum upicola Boiss. var. rupicola ve Arum dioscoridis Sm. taksonlarının anatomik ve morfolojik yönden incelenmesi. Kahramanmaraş Sütçü İmam Üniversitesi Tarım ve Doğa Dergisi, 2020. 23(1): p. 135-147.

12. Konar, A., A. Düzenli, Z. Uygun, Bitkisel bazı enzimlerin çeşitli sütlere pıhtılaştırıcı etkileri. Çukurova Üniversitesi Ziraat Fakültesi Dergisi, 1990. 5(1): p. 149-159.

13. Serteser, A., V. Gök, Süt pıhtılaştırıcıları olarak bazı doğal bitki türlerinin kullanılması. Süt Endüstrisinde Yeni Eğilimler Sempozyumu, 22-23 Mayıs, 2003. 325-328, Bornova, İzmir.

14. Levent, H., Ö. Algan-Cavuldak, Geleneksel kenger kahvesi ve sakızı. III. Geleneksel Gidalar Sempozyumu, 10-12 Mayıs, 2012: p. 618-619.

15. Saydam, İ.B., N. Güzeler, Bazı bitkisel pıhtılaştırıcıların sütü pıhtılaştırma kuvvetleri. III. Geleneksel Gidalar Sempozyumu, 10-12 Mayıs, 2012. 701-703, Konya.

16. Davis, P.H. (ed), Flora of Turkey and The East Aegean Islands. 1965-1985, Edinburgh: Edinburgh Univ. Press. 


\section{EK.1 YOĞURT DUYUSAL ANALIZ FORMU}

Birazdan size Yoğurt örnekleri servis edilecek ve size ürünün bazı kriterleri hakkındaki düşünceleriniz sorulacaktır. Lütfen;

1-Size verilen Yoğurt örneklerini aşağıda verilen sıraya göre renk-görünüş, tat-aroma, kıvam ve genel beğeniniz yönünden değerlendiriniz.

2-Ürünün sizde bıraktığı etkiye göre, aşağıdaki skalayı kullanarak 1 ile 10 arasında bir numarayı daire içerisine alınız.

Puanlandırmada, $1=$ Çok çok kötü, $5=$ Ne iyi ne kötü, $10=$ Çok çok iyi’ye eşittir.

3- Ürün ile ilgili varsa yapmak istediğiniz önerileri aşağıda ayrılan kısma yazınız.

4-Her ürünü tattıktan sonra, diğerine geçmeden önce ağzınızı su ile çalkalayınız.

Sizin yapacağınız dürüst bir puanlama bizlerin çalışmasına yön verecektir.

RENK-GÖRÜNÜŞ

Biarum aleppicum

$\begin{array}{llllllllll}1 & 2 & 3 & 4 & 5 & 6 & 7 & 8 & 9 & 10\end{array}$

Biarum bovei

$\begin{array}{llllllllll}1 & 2 & 3 & 4 & 5 & 6 & 7 & 8 & 9 & 10\end{array}$

Arum rupicola

$\begin{array}{llllllllll}1 & 2 & 3 & 4 & 5 & 6 & 7 & 8 & 9 & 10\end{array}$

TAT-AROMA

Biarum aleppicum

$\begin{array}{llllllllll}1 & 2 & 3 & 4 & 5 & 6 & 7 & 8 & 9 & 10\end{array}$

Biarum bovei

$\begin{array}{llllllllll}1 & 2 & 3 & 4 & 5 & 6 & 7 & 8 & 9 & 10\end{array}$

Arum rupicola

$\begin{array}{llllllllll}1 & 2 & 3 & 4 & 5 & 6 & 7 & 8 & 9 & 10\end{array}$

KIVAM

Biarum aleppicum

$\begin{array}{llllllllll}1 & 2 & 3 & 4 & 5 & 6 & 7 & 8 & 9 & 10\end{array}$

Biarum bovei

$\begin{array}{llllllllll}1 & 2 & 3 & 4 & 5 & 6 & 7 & 8 & 9 & 10\end{array}$

Arum rupicola

$\begin{array}{llllllllll}1 & 2 & 3 & 4 & 5 & 6 & 7 & 8 & 9 & 10\end{array}$

GENEL KABUL EDİLEBİLIRLIK

Ürün hakkındaki diğer düşünceleriniz:

Not: Lütfen örnekleri tercihinize göre sıralayınız.

Ürün hakkındaki diğer düşünceleriniz:

Not: Lütfen örnekleri tercihinize göre sıralayınız. 